\title{
Effects of sweetener sucralose on diet preference, growth performance and hematological and biochemical parameters of weaned piglets
}

\author{
Wenwei Zhang ${ }^{1}$, Holden $\mathrm{He}^{2}$, Limin Gong ${ }^{1}$, Wenqing Lai ${ }^{1}$, Bing Dong ${ }^{1}$, and Liying Zhang ${ }^{1}$ **
}

* Corresponding Author: Liying Zhang Tel: +86-10-62731272, Fax: +86-10-62733700,

E-mail: zhangliying01@sina.com

'State Key Laboratory of Animal Nutrition, Ministry of Agriculture Feed Centre, China Agricultural University, Beijing 100193, China

${ }^{2}$ Nanjing Jinhe Yikang Biotechnology, Jiangbei New Area, Nanjing 210043, China

\section{ORCID}

Wenwei Zhang

https://orcid.org/0000-0002-4176-4483 Holden He

https://orcid.org/0000-0002-8378-9355 Limin Gong

https://orcid.org/0000-0002-4408-3974

Wenging Lai

https://orcid.org/0000-0002-3894-1223

Bing Dong

https://orcid.org/0000-0002-1150-3493

Liying Zhang

https://orcid.org/0000-0003-3991-5075

Submitted Nov 17, 2018; Revised Feb 1, 2019; Accepted May 25, 2019
Objective: Two experiments were conducted to investigate the effects of dietary sucralose on diet preference and growth performance of weaned piglets, and a third experiment was a 28-d safety study to examine if high-dose sucralose could affect the health state of weaned piglets.

Methods: In experiment one, 48 piglets had free access to a corn-soybean based diet and the same diet supplemented with $150 \mathrm{mg} / \mathrm{kg}$ sucralose for $15 \mathrm{~d}$. In experiment two, 180 piglets were blocked into 5 treatments with 6 replications. They were fed basal diets supplemented with $0,75,150,225$, and $300 \mathrm{mg} / \mathrm{kg}$ sucralose for 28 days. In experiment three, 108 piglets were randomly assigned to 3 treatments and fed diets supplemented with 0, 150 (suitable level), and 1,500 (ten-fold suitable level) $\mathrm{mg} / \mathrm{kg}$ sucralose for $28 \mathrm{~d}$.

Results: The experiment 1 showed that piglets preferred $(p<0.05)$ diets containing sucralose during experimental period. In experiment 2, piglets fed a diet supplemented with $150 \mathrm{mg} / \mathrm{kg}$ sucralose had a higher average daily gain (ADG) and average daily feed intake (ADFI) than pigs in the control group and other treatment groups during the experiment period. The concentrations of sucralose over $150 \mathrm{mg} / \mathrm{kg}$ may decrease feed intake. However, no difference in feed conversion ratio was observed. In experiment 3, piglets fed diet supplemented with $150 \mathrm{mg} / \mathrm{kg}$ sucralose had a higher ADG and ADFI than that of pigs in the control group and $1,500 \mathrm{mg} / \mathrm{kg}$ treatment groups during the experiment period. Clinical blood metabolites, organ index and histological morphology were not significantly different between sucralose treatments.

Conclusion: Sucralose can promote feed intake and thereby improve growth performance of weaned piglets. Moreover, inclusion of $1,500 \mathrm{mg} / \mathrm{kg}$ sucralose was demonstrated to have no observed adverse effects. Supplementing $150 \mathrm{mg} / \mathrm{kg}$ sucralose for weaned piglets is recommended in this study.

Keywords: Sucralose; Weaned Piglet; Diet Preference; Growth Performance; Hematological Parameter

\section{INTRODUCTION}

Weaning stress causes many problems for piglets, such as low feed intake, poor growth performance, high morbidity and high mortality [1]. The decrease in feed intake also results in malnutrition, reduction in transient growth rate and intestinal dysfunction [2]. Enhancing feed intake in the weaned pig will prevent villous atrophy, reducing post-weaning diarrhea and stimulate growth. Therefore, it is critical to improve feed intake. Efforts can be made to enhance feed intake such as optimizing feed formula, improving diet digestibility, providing palatable feedstuffs, flavors and taste enhancers [3]. Sweetened feed provided during weanling period can reduce post weaned stress and can benefit feed intake recover in piglets [4]. Some studies have shown that diets supplemented with sweeteners, such as sucrose, 
lactose, glucose [5], or high-intensity artificial sweeteners, such as saccharin [6] and neotame [7], increase feed intake and weight in newly weaned pigs. Kennedy and Baldwin [8] reported sucrose was more attractive than glucose or lactose to pigs. Some artificial sweeteners have bitter aftertaste or metallic odors, or the sweet characteristic is somewhat different from that of sucrose [9-11]. Sweet taste is a natural preference in humans and pigs [12]. Since the number of taste buds in the tongue of pigs are 3 to 4 times more than that of humans [13], pigs are more sensitive to sweet taste. Thus, sweeteners, which have similar taste to sucrose, may be better suited to improve feed intake in the early post-weaning period.

Sucralose (1,6-dichloro-1,6-dideoxy- $\beta$-D-fruct-ofuranosyl4-chloro-4-deoxy-x-D-galactopyranoside) is a non-nutritive artificial sweetener, which is made from sucrose in a fivestep process. Through the process, three atoms of chlorine are selective substitutes for three hydroxyl groups in the sucrose molecule [14] and thereby sucralose is 600 times sweeter than sucrose [15]. Extensive databases of studies on mice, rats, rabbits and dogs shows sucralose is non-teratogenic, non-carcinogenic and non-mutagenic and does not produce reproductive toxicity [16]. Due to its sugar-like taste, lack of bitter aftertaste, stability at high temperature, and long shelflife $[14,17]$, sucralose has been widely used as a sweetener and flavor enhancer in the food industry [18]. Hence, sucralose could be an ideal feed additive for weaned piglets to stimulate feed intake and consequently improve growth performance of weaned piglets. However, to our knowledge, few studies have been conducted on the effects of sucralose on piglets. Therefore, the objective of this study was to investigate the effects of dietary inclusion of sucralose on diet preference, growth performance, and hematological and biochemical parameters of weaned piglets.

\section{MATERIALS AND METHODS}

\section{Animal care}

This study was approved by the Institution Animal Care and Use Committee of China Agricultural University (CAU2017 0801-3).

\section{Animals, diets and experimental design}

All piglets had access to water and creep feed before weaning. Three experiments were performed at the Swine Nutrition Research Center of the National Feed Engineering Technology Research Center (Chengde, Hebei, China). Weaned piglets were raised in an environmentally controlled house with slatted floor pens $\left(1.2 \times 2.0 \mathrm{~m}^{2}\right)$. Each pen was equipped with a nipple drinker and two stainless steel feeders for experiment 1 , and one feeder for experiments 2 and 3. Pigs were allowed ad libitum access to feed and water. The basal diet was a cornsoybean based diet formulated to meet or exceed the NRC
[19] recommendations for weaned piglets (Table 1).

Experiment 1: Experiment 1 was designed to determine if supplementary sucralose could affect diet preference of weaned piglets. Forty-eight weaned piglets $(8.90 \pm 0.09 \mathrm{~kg})$, were blocked by body weight (BW), ancestry and gender and divided into 1 of 2 dietary treatments with 8 pens per treatment and 6 pigs ( 3 male and 3 female) per pen. Piglets from the same sow are distributed equally to each treatment. The diet preference protocol was derived from the Richter-type test called the two-bottle preference test [20]. Each feeder contained one experimental diet: the corn-soybean basal diet (Phase I in Table 1) and the same diet supplemented with $150 \mathrm{mg} / \mathrm{kg}$ sucralose. The experiment lasted for $15 \mathrm{~d}$, including a $5-\mathrm{d}$ adaptation period and a $10-\mathrm{d}$ experimental period. On the first day of adaption period, all pigs were fed creep feed. On $\mathrm{d} 2$, they were fed mixed feed with 1:1 ratio of creep

Table 1. Ingredient and analyzed composition of basal diets (as-fed basis, $\mathrm{g} / \mathrm{kg}$ ) ${ }^{1)}$

\begin{tabular}{lcc}
\hline \multirow{2}{*}{ Items } & \multicolumn{2}{c}{ Basal diet } \\
\cline { 2 - 3 } & Phase I & Phase II \\
\hline Ingredient & 533.8 & 581.6 \\
Ground corn & 177.5 & 159.0 \\
Soybean meal (46\% crude protein) & 163.5 & 130.0 \\
Expanded soybean & 46.4 & 62.1 \\
Dried whey (12\% crude protein) & 27.4 & 26.5 \\
Fish meal & 16.9 & 10.2 \\
Soybean oil & 11.2 & 10.0 \\
Dicalcium phosphate & 7.4 & 5.0 \\
Ground limestone & 2.3 & 3.0 \\
Salt & 3.5 & 3.8 \\
L-Lysine HCl & 1.3 & 1.2 \\
L-Threonine & 1.8 & 1.6 \\
DL-Methionine & 2.0 & 1.0 \\
Choline chloride & 5.0 & 5.0 \\
Vitamin-mineral premix) & & \\
Chemical analysis & 14.9 & 14.7 \\
Digestible energy ${ }^{3)}$ (MJ/kg) & 209.9 & 193.3 \\
Crude protein & 14.6 & 13.8 \\
Lysine & 4.4 & 3.9 \\
Methionine & 7.4 & 6.8 \\
Methionine+cysteine & 7.9 & 7.7 \\
Threonine & 8.5 & 8.2 \\
Calcium & 6.6 & \\
Total phosphorus & & \\
\hline & &
\end{tabular}

${ }^{1)}$ In experiment 1, the basal diet was supplemented with $150 \mathrm{mg} / \mathrm{kg}$ sucralose. In experiment 2, the basal diets were supplemented with 75, 150,225, or $300 \mathrm{mg} /$ kg sucralose (Phase I and II). In experiment 3, the basal diets were supplemented with 150 , or $1,500 \mathrm{mg} / \mathrm{kg}$ sucralose (Phase I and II).

2) Provided per $\mathrm{kg}$ of diet: vitamin $\mathrm{A}, 12,000 \mathrm{IU}$; vitamin $\mathrm{D}_{3}, 2,000 \mathrm{IU}$; vitamin $\mathrm{E}, 30$ $\mathrm{IU}$; vitamin $\mathrm{K}_{3}, 2.5 \mathrm{mg}$; thiamin, $2.5 \mathrm{mg}$; riboflavin, $4 \mathrm{mg}$; pyridoxine, $3 \mathrm{mg}$; vitamin $\mathrm{B}_{12}, 20 \mu \mathrm{g}$; niacin, $40 \mathrm{mg}$; pantothenic acid, $12.5 \mathrm{mg}$; folic acid, $0.7 \mathrm{mg}$; biotin, 0.07 $\mathrm{mg}$; Fe as iron sulfate, $100 \mathrm{mg}$; Cu as copper sulfate, $90 \mathrm{mg}$; Zn as zinc sulfate, $80 \mathrm{mg}$; $\mathrm{Mn}$ as manganese sulfate, $30 \mathrm{mg}$; I as potassium iodide, $0.25 \mathrm{mg}$; Se as sodium selenite, $0.15 \mathrm{mg}$.

${ }^{3)}$ Calculated value according to DE value of each ingredient provided by NRC [19]. 
feed to control diet. And from d 3 to 5, all pigs were fed control diet. The amount of feed consumed was determined daily to calculate feed intake and diet preference percentage. Diet preference was determined using the following equation:

Diet preference percentage

$=$ Intake of one diet $(\mathrm{g}) /$ Total feed intake $(\mathrm{g}) \times 100 \%$

Experiment 2: This experiment was conducted to evaluate the effects of sucralose supplementation on performance of weaned piglets. A total of 180 weaned piglets $(7.95 \pm 0.17 \mathrm{~kg})$, were blocked by BW, ancestry and gender and divided into 1 of 5 dietary treatments with 6 pens per treatment and 6 pigs ( 3 male and 3 female) per pen. Piglets from the same sow are distributed equally to each treatment. The experimental diets were a basal diet (Table 1) supplemented with $0,75,150,225$, or $300 \mathrm{mg} / \mathrm{kg}$ sucralose. The experiment included two phases (d 0 to 14 and 15 to 28) lasting for 28 days. Pigs and feeders were weighed on $\mathrm{d} 0,14$, and 28 to calculate average daily gain (ADG), average daily feed intake (ADFI), and feed efficiency (G:F).

Experiment 3: Experiment 3 was conducted to determine the effects of sucralose on hematological and biochemical parameters of weaned piglets. A total of 108 weaned piglets $(7.97 \pm 0.18 \mathrm{~kg})$, were blocked by BW, ancestry and gender and divided into 1 of 3 dietary treatments with 6 pens per treatment and 6 pigs ( 3 male and 3 female) per pen. Piglets from the same sow are distributed equally to each treatment. Pigs were fed the basal diet (Table 1) or the same diet supplemented with 150 or $1,500 \mathrm{mg} / \mathrm{kg}$ sucralose. The experiment was conducted over 28 days. Pigs and feeders were weighed on $\mathrm{d} 0$, 14, and 28 to calculate ADG, ADFI, and G:F.

On $\mathrm{d} 14$ and 28, one weaned piglet per pen, weighting closest to the average weight for each pen (six piglets per treatment with three female and three male), was chosen for blood sampling after fasting overnight. Blood samples were collected from the anterior vena cava into vacutainer tubes containing EDTAK $_{2}$ (Sanli Medical Technology Development Co. LTD, Liuyang, China) and no anticoagulant to obtain whole blood and serum, respectively. The whole blood was assayed for hematological parameters within 1 hour after sampling. Serum was separated by centrifugation for $10 \mathrm{~min}$ at $3,000 \times \mathrm{g}$ and $4^{\circ} \mathrm{C}$, then stored at $-20^{\circ} \mathrm{C}$ until analysis.

After blood sampling, piglets were weighed, then electrically stunned and killed by exsanguination to obtain intestinal and organ tissues. The heart, liver, spleen, lung, and kidney were weighed to calculate the organ index. Organ and intestinal (middle sections of duodenum, jejunum, and ileum) tissue samples were aseptically isolated, flushed with $0.9 \%$ salt solution, then fixed in $10 \%$ formaldehyde-phosphate buffer, and finally kept at $4^{\circ} \mathrm{C}$ for microscopic assessment.

\section{Chemical analysis of feed}

Ingredients and diets were analyzed according to AOAC [21] procedures including crude protein, total phosphorus, and calcium. For the analysis of most amino acids, ingredients and diets were hydrolyzed in $6 \mathrm{~N} \mathrm{HCl}$ at $110^{\circ} \mathrm{C}$ for 24 hours. The sulfur amino acid content was measured after performic acid oxidation (AOAC) [21]. Amino acid analyses were performed using High Performance Liquid Chromatography (Hitachi L-8800 Amino Acid Analyzer, Tokyo, Japan).

\section{Hematological and serum biochemical parameters analysis}

The hematological parameters were determined using a Sysmex Microcell Counter CT-180 (Tokyo, Japan) and included white blood cells, red blood cells, hemoglobin, hematocrit, mean corpuscular volume, mean corpuscular hemoglobin, mean corpuscular hemoglobin concentration, red cell distribution width, platelets, mean platelet volume, platelet distribution width, neutrophils, eosinophils, basophils, lymphocytes, and monocytes.

Serum biochemical parameters in experiment 3 included total protein, albumin, glucose, triglyceride, total cholesterol, creatinine, urea nitrogen, alanine aminotransferase, aspartate aminotransferase, and alkaline phosphatase were measured using commercially-available kits (BioSino Biotechnology and Science Incorporated Beijing, China) using an Automatic Biochemical Analyzer (Hitachi 7160, High Technologies Corporation, Tokyo, Japan). These metabolites were included to cover a wide range of toxicities with possible effects on electrolyte balance, metabolism (carbohydrates, protein, fat, and minerals), and damage to the major organ systems.

\section{Histopathology analysis}

The tissue samples were fixed in $10 \%$ buffered formalin for $24 \mathrm{~h}$ and then treated following dehydration, clearing and paraffin embedding procedures. Paraffin sections of $5 \mu \mathrm{m}$ thickness were stained with hematoxylin and eosin. The histopathologic evaluation of organs was accessed according to the pathological scoring standards [22].

\section{Statistical analysis}

In experiment 1 , each pen was considered as the experimental unit. Significant differences between data were analyzed using paired $t$-test in SAS 9.2 (SAS, Institute, Cary, NC, USA) statistical software, and differences were considered statistically significant at $\mathrm{p}<0.05$.

The data from experiment 2 and 3 were analyzed as a randomized complete block design using the general linear model procedure of SAS 9.2 (SAS Institute, USA). Each pen was considered as the experimental unit. Statistical significance was assessed by analysis of variance. Data from experiment 2 and 3 were analyzed by using orthogonal polynomial contrast. Sig- 
nificance was taken at $\mathrm{p}<0.05$ and tendency at $0.05 \leq \mathrm{p}<0.10$.

A probability level of $\mathrm{p}<0.05$ was considered statistically significant. In experiment $2, \mathrm{ADG}$ and ADFI during phase I, II and the whole period ( 0 to 28 ) was analyzed by a quadratically fitted line model $\left(y=a \times x^{2}+b \times x+c\right.$, the maximum quadratic $=-b /[2 a])$, respectively. Data in experiment 2 was subjected to the nonlinear regression procedures of GraphPad Prism (GraphPad Prism 7.0, GraphPad Software, San Diego, CA, USA).

\section{RESULTS}

\section{Experiment 1}

Compared to control group (Table 2), dietary supplementation of $150 \mathrm{mg} / \mathrm{kg}$ sucralose was consumed significantly more $(\mathrm{p}<0.05)$ than the control diet during $\mathrm{d} 1,4,7$, and the entire experimental period ( $\mathrm{d} 1$ to 10$)$. Accordingly, the diet preference percentage of sucralose treatment groups was higher $(\mathrm{p}<$ 0.05 ) than control group on day $1,4,7$, and the entire experimental period ( $\mathrm{d} 1$ to 10$)$.

\section{Experiment 2}

The effect of graded levels of sucralose on the growth performance of weaned piglets is shown in Table 3. The ADG of pigs in $150 \mathrm{mg}$ sucralose treatment group was significantly higher $(\mathrm{p}<0.05)$ than the other groups during phase II ( 15 to 28 ) and the entire experimental period (d 0 to 28). Compared to 0 (control group), 225 and $300 \mathrm{mg}$ dietary sucralose treatment groups, dietary supplementation with $150 \mathrm{mg}$ sucralose significantly increased ADFI during phase I (d 0 to 14), phase II (d 15 to 28 ) and the entire experimental period
Table 2. The effects of dietary sucralose on diet preference of weaned piglets (experiment 1)

\begin{tabular}{lcccc}
\hline & \multicolumn{2}{c}{$\begin{array}{c}\text { Dietary sucralose } \\
\text { level }(\mathbf{m g} / \mathbf{k g})\end{array}$} & & \\
\cline { 2 - 3 } Items & $\mathbf{0}$ & $\mathbf{1 5 0}$ & & p-value \\
\cline { 2 - 3 } & & & & \\
\cline { 2 - 3 } Diet preference percentage (\%) & & & & \\
d 1 & 44.9 & 55.1 & 2.64 & 0.007 \\
d 2 & 50.4 & 49.6 & 4.19 & 0.848 \\
d 3 & 48.7 & 51.3 & 2.96 & 0.415 \\
d 4 & 45.3 & 54.7 & 3.65 & 0.365 \\
d 5 & 48.4 & 51.6 & 2.05 & 0.165 \\
d 6 & 48.2 & 51.8 & 1.55 & 0.054 \\
d 7 & 45.2 & 54.8 & 3.61 & 0.034 \\
d 8 & 47.9 & 52.1 & 4.10 & 0.351 \\
d 9 & 45.7 & 54.2 & 5.91 & 0.197 \\
d 10 & 48.2 & 51.8 & 4.46 & 0.435 \\
Average diet preference & 47.3 & 52.6 & 3.73 & 0.005 \\
$\quad$ percentage (d 1 to 10) & & & & \\
\hline
\end{tabular}

Data are the means of 8 replications.

SEM, pooled standard error of the mean.

(d 0 to 28). Dietary Supplementation with sucralose could improve ADFI. However, when the included level of sucralose was over $150 \mathrm{mg} / \mathrm{kg}$, ADFI was reduced. No significant difference in $\mathrm{G}$ : $\mathrm{F}$ was found among treatments during any experimental period. According to a fitted quadratic plot model in Figure 1, optimal sucralose inclusion level to maximum ADG was $146.7 \mathrm{mg} / \mathrm{kg}$ during phase $\mathrm{I}, 150.1 \mathrm{mg} / \mathrm{kg}$ in phase II, and $149.6 \mathrm{mg} / \mathrm{kg}$ during the entire experiment period (d 0 to 28). According to (Figure 2), the quadratic plot model on ADFI indicated that the optimal dosages of sucralose in weaned piglets were $137.8 \mathrm{mg} / \mathrm{kg}$ in phase I, $145.8 \mathrm{mg} / \mathrm{kg}$ in

Table 3. The effects of graded levels of sucralose on the performance of weaned piglets (experiment 2)

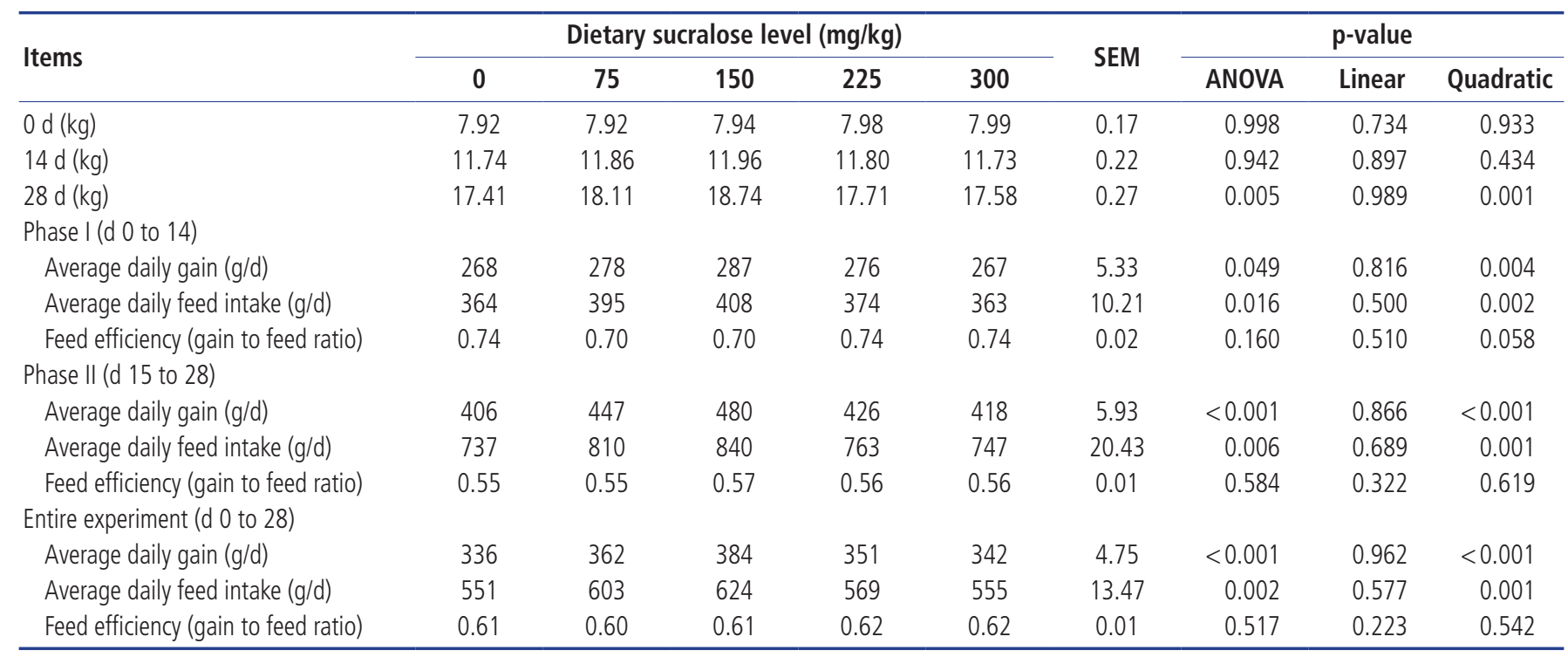

Data are the means of 6 replications.

SEM, pooled standard error of the mean; ANOVA, analysis of variance. 


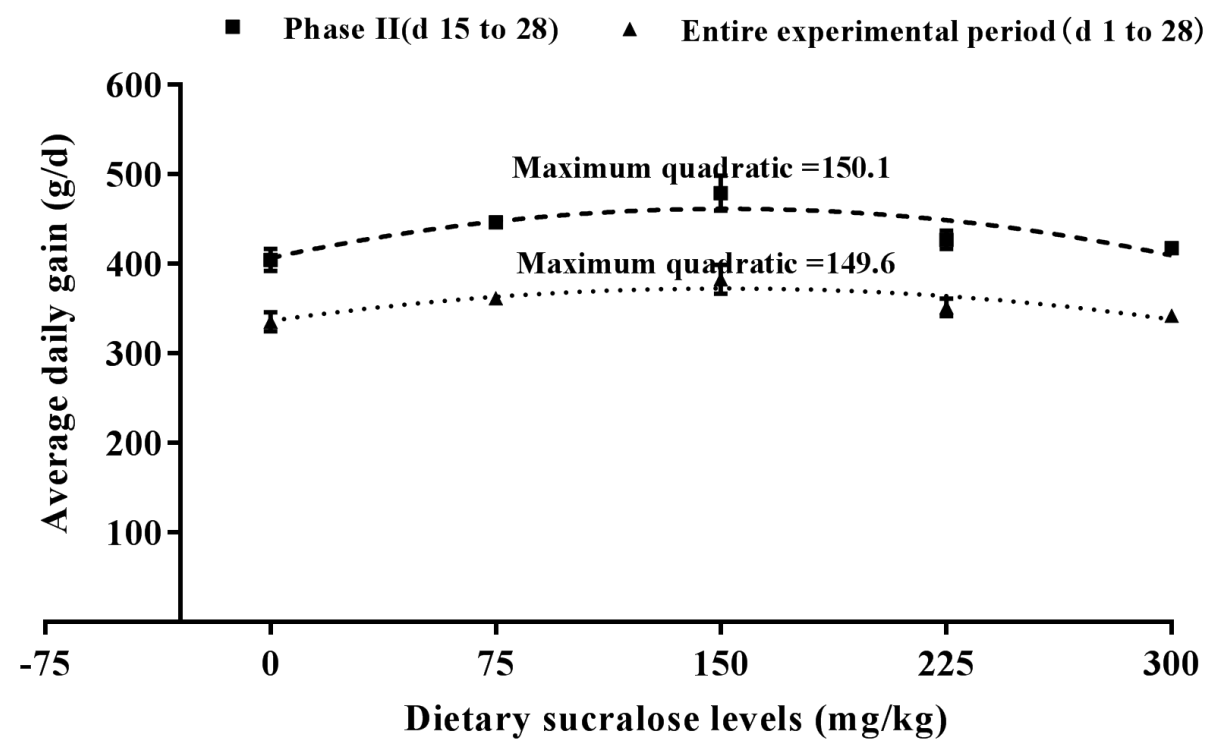

Figure 1. Fitted quadratic plot of average daily gain as a function of dietary sucralose for weaned piglets (experiment 2). The optimal dietary sucralose for phase I was $146.7 \mathrm{mg} / \mathrm{kg}\left(\mathrm{y}=-0.0008 \mathrm{x}^{2}+0.2347 \mathrm{x}+265.86, R^{2}=0.91, p<0.01\right)$, and the SE for the estimated parameters of $a(-0.0008), b(0.2347), c(265.86)$ were $0.0005,0.1545$, 9.783 , respectively. The optimal dietary sucralose for phase II was $150.1 \mathrm{mg} / \mathrm{kg}\left(y=-0.0024 x^{2}+0.7205 x+406.70, R^{2}=0.74\right.$, $\left.p<0.01\right)$, and the SE for the estimated parameters of a $(-0.0024), b(0.7205), c(406.70)$ were $0.0006,0.1890,11.96$, respectively. The optimal dietary sucralose for entire experiment period was $149.6 \mathrm{mg} / \mathrm{kg}(\mathrm{y}$ $\left.=-0.0016 x^{2}+0.4788 x+336.21, R^{2}=0.79, p<0.01\right)$, and the SE for the estimated parameters of a $(-0.0016), b(0.4788), c(336.21)$ were $0.0005,0.1569,9.936$, respectively. SE, standard error.

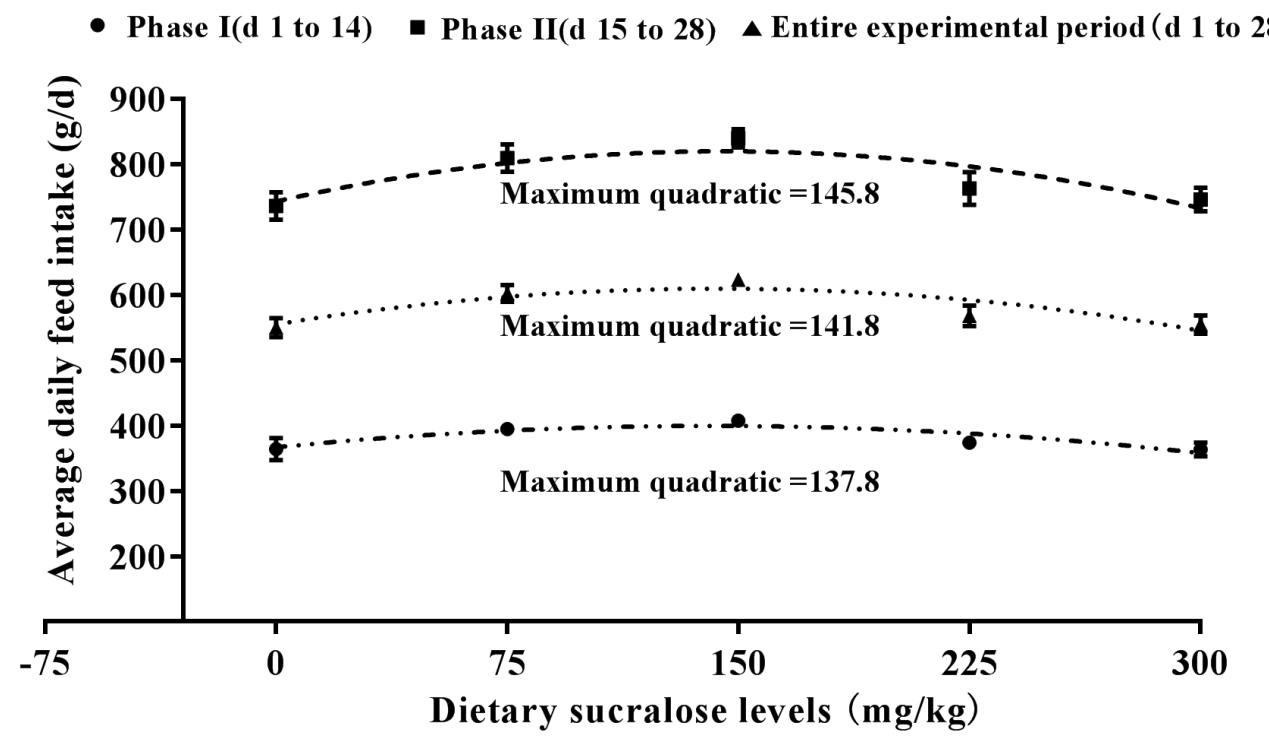

Figure 2. Fitted quadratic plot of average daily feed intake as a function of dietary sucralose for weaned piglets (experiment 2). The optimal dietary sucralose for phase I was $137.8 \mathrm{mg} / \mathrm{kg}\left(y=-0.0017 x^{2}+0.4684 x+366.69, R^{2}=0.81, p<0.01\right)$, and the SE for the estimated parameters of a $(-0.0017), b(0.4684), c(366.69)$ were 0.0005 , $0.1545,9.783$, respectively. The optimal dietary sucralose for phase II was $145.8 \mathrm{mg} / \mathrm{kg}\left(y=-0.0036 x^{2}+1.0497 x+744.09, R^{2}=0.78, p<0.01\right)$, and the $S E$ for the estimated parameters of a $(-0.0036), b(1.0497), c(744.69)$ were $0.0010,0.3169,20.06$, respectively. The optimal dietary sucralose for entire experiment period was $141.8 \mathrm{mg} / \mathrm{kg}\left(\mathrm{y}=-0.0027 \mathrm{x}^{2}+0.7655 \mathrm{x}+555.74, \mathrm{R}^{2}=0.78, \mathrm{p}<0.01\right)$, and the SE for the estimated parameters of a $(-0.0026), \mathrm{b}(0.7655), \mathrm{c}(555.74)$ were 0.00068 , $0.2114,13.38$, respectively. SE, standard error.

phase II, and $141.8 \mathrm{mg} / \mathrm{kg}$ during the entire experiment period (d 0 to 28 ), respectively.

\section{Experiment 3}

In experiment 3, piglets fed diet supplemented with $150 \mathrm{mg} / \mathrm{kg}$ sucralose had higher ADG and ADFI than that of pigs in the control group and 1,500 $\mathrm{mg} / \mathrm{kg}$ treatment groups during the experiment period (Table 4). Hematological parameters (Table 5), serum biochemical parameters (Table 6), and organ index (Table 7) were not significantly different among all treatment groups. Figure 3 shows the histological structures of liver, kidney and small intestines observed in all pigs fed the different 
Table 4. The effects of graded levels of sucralose on the performance of weaned piglets (experiment 3)

\begin{tabular}{|c|c|c|c|c|c|c|c|}
\hline \multirow{2}{*}{ Items } & \multicolumn{3}{|c|}{ Dietary sucralose level (mg/kg) } & \multirow{2}{*}{ SEM } & \multicolumn{3}{|c|}{$\mathrm{p}$-value } \\
\hline & 0 & 150 & 1,500 & & ANOVA & Linear & Quadratic \\
\hline $0 \mathrm{~d}(\mathrm{~kg})$ & 7.93 & 7.96 & 8.03 & 0.18 & 0.918 & 0.683 & 0.947 \\
\hline $14 \mathrm{~d}(\mathrm{~kg})$ & 12.10 & 12.67 & 12.25 & 0.20 & 0.137 & 0.729 & 0.051 \\
\hline $28 \mathrm{~d}(\mathrm{~kg})$ & 17.05 & 18.61 & 17.42 & 0.29 & 0.001 & 0.418 & $<0.001$ \\
\hline \multicolumn{8}{|l|}{ Phase I ( $\mathrm{d} 0$ to 14$)$} \\
\hline Average daily gain (g/d) & 292 & 336 & 301 & 4.48 & $<0.001$ & 0.092 & $<0.001$ \\
\hline Average daily feed intake (g/d) & 385 & 450 & 395 & 16.32 & 0.043 & 0.951 & 0.014 \\
\hline Feed efficiency (gain to feed ratio) & 0.76 & 0.75 & 0.74 & 0.02 & 0.790 & 0.577 & 0.684 \\
\hline \multicolumn{8}{|l|}{ Phase II (d 15 to 28$)$} \\
\hline Average daily gain (g/d) & 355 & 423 & 369 & 9.00 & $<0.001$ & 0.194 & $<0.001$ \\
\hline Average daily feed intake (g/d) & 730 & 852 & 747 & 26.76 & 0.012 & 0.308 & 0.005 \\
\hline Feed efficiency (gain to feed ratio) & 0.49 & 0.50 & 0.49 & 0.01 & 0.941 & 0.739 & 0.912 \\
\hline \multicolumn{8}{|l|}{ Entire experiment ( $\mathrm{d} 0$ to 28$)$} \\
\hline Average daily gain (g/d) & 323 & 379 & 335 & 4.78 & $<0.001$ & 0.052 & $<0.001$ \\
\hline Average daily feed intake ( $\mathrm{g} / \mathrm{d}$ ) & 558 & 651 & 579 & 13.26 & $<0.001$ & 0.287 & $<0.001$ \\
\hline Feed efficiency (gain to feed ratio) & 0.58 & 0.58 & 0.58 & 0.01 & 0.943 & 0.735 & 0.968 \\
\hline
\end{tabular}

Data are the means of 6 replications.

SEM, pooled standard error of the mean; ANOVA, analysis of variance.

Table 5. The effects of graded levels of sucralose on hematological parameters of weaned piglets (experiment 3)

\begin{tabular}{|c|c|c|c|c|c|c|c|}
\hline \multirow{2}{*}{ Items } & \multicolumn{3}{|c|}{ Dietary sucralose level $(\mathrm{mg} / \mathrm{kg})$} & \multirow{2}{*}{ SEM } & \multicolumn{3}{|c|}{$\mathrm{p}$-value } \\
\hline & 0 & 150 & 1,500 & & ANOVA & Linear & Quadratic \\
\hline White blood cells $\left(10^{9} / \mathrm{L}\right)$ & 18.38 & 22.65 & 15.85 & 2.43 & 0.169 & 0.168 & 0.188 \\
\hline Red blood cells $\left(10^{12} / \mathrm{L}\right)$ & 6.19 & 5.97 & 6.32 & 0.21 & 0.524 & 0.417 & 0.432 \\
\hline Hemoglobin (g/L) & 100.17 & 100.50 & 104.67 & 3.69 & 0.639 & 0.352 & 0.982 \\
\hline Hematocrit $(\%)$ & 0.38 & 0.38 & 0.40 & 0.01 & 0.587 & 0.303 & 0.847 \\
\hline Mean corpuscular volume (\%) & 62.05 & 64.17 & 63.22 & 1.46 & 0.601 & 0.880 & 0.326 \\
\hline Mean corpuscular hemoglobin (\%) & 16.18 & 16.83 & 16.63 & 0.42 & 0.541 & 0.735 & 0.298 \\
\hline Mean corpuscular hemoglobin concentration (\%) & 261.00 & 262.17 & 262.67 & 2.96 & 0.920 & 0.751 & 0.805 \\
\hline Red cell distribution width (\%) & 21.73 & 21.17 & 20.25 & 0.75 & 0.389 & 0.196 & 0.684 \\
\hline Platelet $\left(10^{9} / \mathrm{L}\right)$ & 495.67 & 479.17 & 453.67 & 47.07 & 0.819 & 0.554 & 0.849 \\
\hline Mean platelet volume (fL) & 12.00 & 11.60 & 12.15 & 0.47 & 0.703 & 0.593 & 0.526 \\
\hline Platelet distribution width (\%) & 15.63 & 15.00 & 12.77 & 1.12 & 0.196 & 0.078 & 0.821 \\
\hline Neutrophils $\left(10^{9} / \mathrm{L}\right)$ & 2.26 & 3.20 & 1.00 & 1.32 & 0.513 & 0.325 & 0.558 \\
\hline Eosinophils $\left(10^{9} / \mathrm{L}\right)$ & 0.20 & 0.20 & 0.26 & 0.55 & 0.565 & 0.294 & 0.943 \\
\hline Basophils $\left(10^{9} / \mathrm{L}\right)$ & 1.17 & 2.73 & 1.40 & 0.75 & 0.310 & 0.652 & 0.149 \\
\hline Lymphocyte (\%) & 74.97 & 69.28 & 78.40 & 6.21 & 0.589 & 0.458 & 0.483 \\
\hline Monocyte (\%) & 5.02 & 5.37 & 5.15 & 0.44 & 0.583 & 0.979 & 0.579 \\
\hline
\end{tabular}

Data are the means of 6 replications.

SEM, pooled standard error of the mean; ANOVA, analysis of variance.

diets for 28 days. No significant changes were observed in histopathological analysis of tissues compared to control group.

\section{DISCUSSION}

Most mammals have a preference for sweet feed [23]. Among those with a sweet preference, pigs prefer sweet substances because they have large number of taste buds in the tongue [24]. In the present study, preference tests showed that weaned piglets prefer the diet supplemented with sucralose, and dietary supplementation with $150 \mathrm{mg} / \mathrm{kg}$ sucralose could significantly increase feed intake.

Weaned piglets have a preference for a sweet taste, especially sucrose [12]. Sucrose is widely used as sweetener in feed. However, Guzmán-Pino et al [25] reported that excessive calories ingested from a sucrose solution may result in decreased feed intake, and further reducing weight gain of weaned piglets. Sucralose is a non-caloric sweetener that is synthesized by selective chlorination of sucrose at three of the primary hydroxyl groups, involving inversion of configuration at car- 
Table 6. The effects of graded levels of sucralose on serum biochemical parameters of weaned piglets (experiment 3)

\begin{tabular}{|c|c|c|c|c|c|c|c|}
\hline \multirow{2}{*}{ Items } & \multicolumn{3}{|c|}{ Dietary sucralose level (mg/kg) } & \multirow{2}{*}{ SEM } & \multicolumn{3}{|c|}{ p-value } \\
\hline & 0 & 150 & 1,500 & & ANOVA & Linear & Quadratic \\
\hline Total protein (g/L) & 42.47 & 40.50 & 44.53 & 3.17 & 0.675 & 0.469 & 0.619 \\
\hline Albumin (g/L) & 25.70 & 24.15 & 25.72 & 2.05 & 0.826 & 0.794 & 0.582 \\
\hline Glucose (mmol/L) & 5.59 & 5.30 & 6.30 & 0.52 & 0.404 & 0.217 & 0.613 \\
\hline Triglyceride (mmol/L) & 0.47 & 0.45 & 0.43 & 0.06 & 0.908 & 0.732 & 0.793 \\
\hline Total cholesterol (mmol/L) & 1.78 & 1.59 & 1.93 & 0.17 & 0.407 & 0.303 & 0.394 \\
\hline Creatinine ( $\mu \mathrm{mol} / \mathrm{L})$ & 66.15 & 58.53 & 72.50 & 7.28 & 0.419 & 0.303 & 0.414 \\
\hline Urea nitrogen (mmol/L) & 2.21 & 1.91 & 2.98 & 0.37 & 0.144 & 0.069 & 0.462 \\
\hline Alanine aminotransferase (U/L) & 30.97 & 27.93 & 29.77 & 3.22 & 0.801 & 0.985 & 0.513 \\
\hline Aspartate transaminase (U/L) & 31.77 & 25.32 & 40.67 & 7.27 & 0.350 & 0.213 & 0.466 \\
\hline Alkaline phosphatase (U/L) & 269.57 & 240.58 & 180.02 & 26.20 & 0.078 & 0.029 & 0.579 \\
\hline
\end{tabular}

Data are the means of 6 replications.

SEM, pooled standard error of the mean; ANOVA, analysis of variance.

Table 7. The effects of graded levels of sucralose on organ index of weaned piglets ( $\mathrm{g} / \mathrm{kg}$ body weight, experiment 3 )

\begin{tabular}{|c|c|c|c|c|c|c|c|}
\hline \multirow{2}{*}{ Items } & \multicolumn{3}{|c|}{ Dietary sucralose level (mg/kg) } & \multirow{2}{*}{ SEM } & \multicolumn{3}{|c|}{ p-value } \\
\hline & 0 & 150 & 1,500 & & ANOVA & Linear & Quadratic \\
\hline Heart & 5.43 & 5.16 & 5.23 & 0.22 & 0.678 & 0.742 & 0.421 \\
\hline Liver & 31.95 & 31.27 & 31.12 & 1.59 & 0.926 & 0.786 & 0.782 \\
\hline Spleen & 2.44 & 2.29 & 2.57 & 1.59 & 0.619 & 0.437 & 0.562 \\
\hline Lung & 11.53 & 10.99 & 10.82 & 0.54 & 0.639 & 0.483 & 0.534 \\
\hline Kidney & 2.58 & 2.50 & 2.62 & 0.10 & 0.701 & 0.563 & 0.548 \\
\hline
\end{tabular}

Data are the means of 6 replicates.

SEM, pooled standard error of the mean; ANOVA, analysis of variance.

bon-4, from the gluco-to the galactoanalogue [26]. Meanwhile, sucralose has a sweetness potency of about 600 times that of sucrose [15], thus adding a small amount of sucralose into the feed can achieve a similar effect to the sweetness of sucrose.

There have been many reports of sweeteners fed to pigs, but growth performance results are inconsistent. Sweeteners like neohesperidin dihydrochalcone (trade name Sucram) [4] and neotame have been reported to improve the performance of pigs. Adding the artificial sweetener, neotame, in the feed can improve palatability and feed intake for piglets over $35 \mathrm{~d}$ [7]. The supplement of sucralose can improve ADG and ADFI of weaned piglets during phase I ( $\mathrm{d} 0$ to 14 ) and phase II (d 15 to 28 ) in the present study. The present study showed that over $28 \mathrm{~d}$ optimum growth rate and feed intake were supported on diets containing 149.6 and $141.8 \mathrm{mg} / \mathrm{kg}$ sucralose, respectively. Experiment 2 mainly focused on the efficacy evaluation and to determine the suitable inclusion level in diets. The result found a clear reduction of ADFI when sucralose was dosed over $150 \mathrm{mg} / \mathrm{kg}$. The growth performance (ADG and ADFI) started to decrease when 225 and $300 \mathrm{mg} / \mathrm{kg}$ sucralose was included in diets. It was the decreasing the palatability of the diet that further reduced ADFI and ADG, not that sucralose had adverse effects on health of weaned piglets. However, several researches on other sweeteners such as sorbitol [27] and stevia [28] suggested that no beneficial effects on pigs were observed. These responses are likely to be affected by the age and weight of the pig at weaning and by the composition of the basal diet. The stevia-containing diets did not increase feed intake of weaned piglets [28]. Similarly, there were no effects of the dietary sorbitol levels were observed on growth performance [27]. The positive effects of sucralose were observed both during phase I ( 0 to 14 ) and phase II (d 15 to 28 ) in the present study. However, some studies $[4,29]$ found that pigs required a certain period of time before positive effects of sweeteners on their performance could be observed.

The safety of sweeteners has been controversial [30]. Thus, the safety assessment of sucralose is an important aspect before its application as a feed additive. Experiment 3 mainly focused on tolerance evaluation and ensuring whether the suitable inclusion level of $150 \mathrm{mg} / \mathrm{kg}$ sucralose is safe for weaned piglets. If ten-fold suitable level of sucralose showed no indication of toxicity in weaned pigs, then it means that weaned pigs could tolerate ten-fold suitable level of sucralose. In other words, the recommended suitable level of $150 \mathrm{mg} / \mathrm{kg}$ is safe for weaned piglets [31]. The safety of sucralose has been the subject of rigorous and extensive investigation. The maximum tolerable doses were due to poor palatability of 

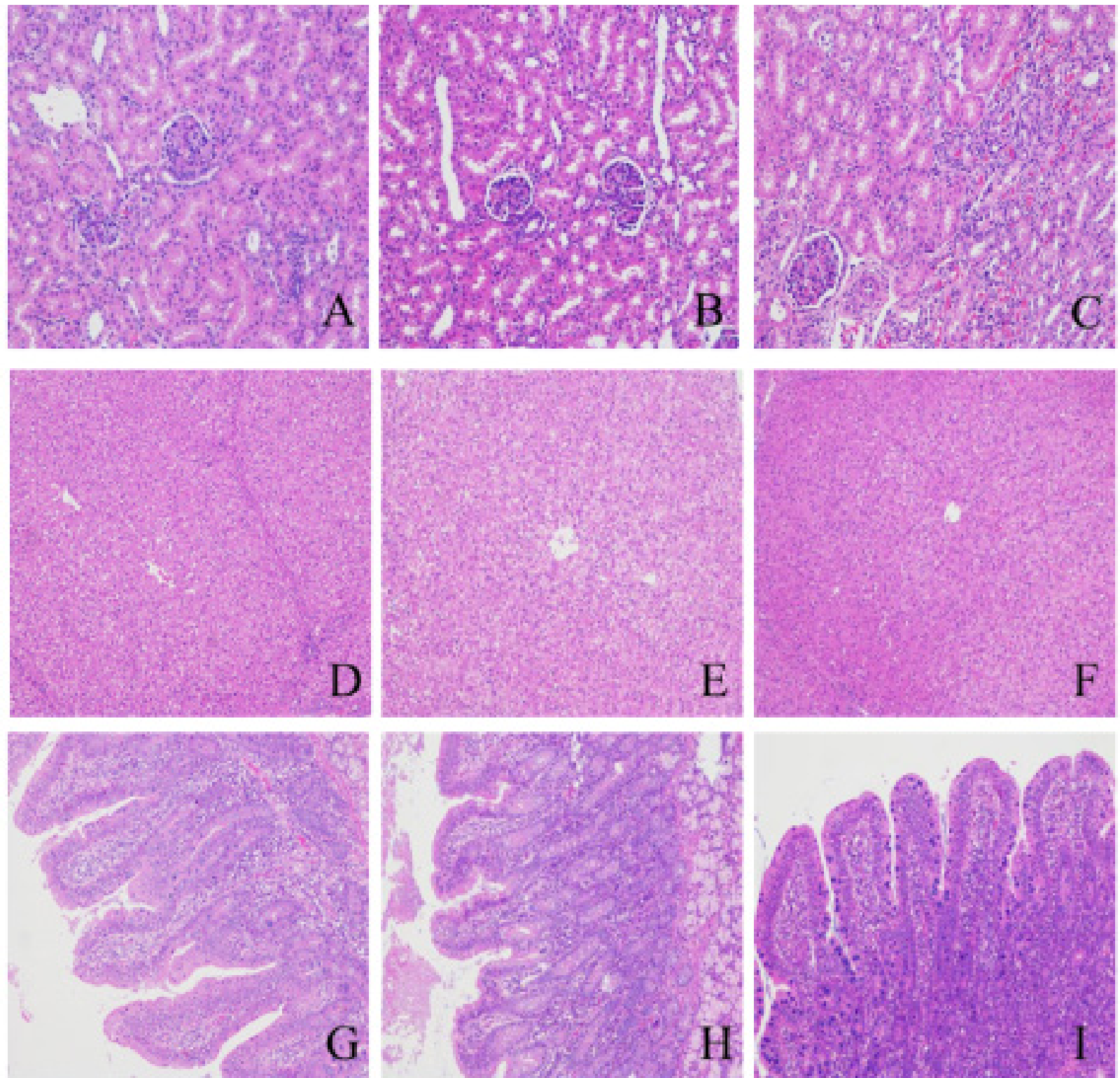

Figure 3. Histopathological examination of the kidney (H\&E, 200x), liver and intestinal (H\&E, 100x). (A), (B), and (C) were histopathological examinations of the kidney of pigs fed the basal diet and basal diet with 150 or 1,500 mg/kg sucralose, respectively. (D), (E), and (F) were histopathological examinations of the liver of pigs fed the basal diet, and basal diet with 150 or 1,500 mg/kg sucralose, respectively. $(\mathrm{G}),(\mathrm{H})$, and (I) were histopathological examinations of the small intestinal (duodenum) of pigs fed the basal diet, and basal diet with 150 or $1,500 \mathrm{mg} / \mathrm{kg}$ sucralose, respectively. H\&E, haematoxylin and eosin.

high doses of sucralose, not toxicity [14]. This study demonstrated that sucralose has negative effect on ADFI of weaned piglets when including level is over $150 \mathrm{mg} / \mathrm{kg}$ in diet. Grice and Goldsmith [14] also reported that $30 \mathrm{~g} / \mathrm{kg} / \mathrm{d}$ sucralose could reduce feed intake in rats. This may be that a high level of sucralose decreases palatability of diet. In the present study, dietary supplementation of sucralose up to $1,500 \mathrm{mg} / \mathrm{kg}$ had no detrimental effects on hematological parameters, biochemical parameters and organ index, which are in accordance with studies in the rat and dogs. Goldsmith et al [32] reported that dietary sucralose levels of up to $25 \mathrm{~g} / \mathrm{kg} / \mathrm{d}$ had no adverse effects on biochemical parameters, organ index and hematological parameters in rats. They also found that administration of 1,500 or $3,000 \mathrm{mg} / \mathrm{kg} / \mathrm{d}$ sucralose had no sucralose-related toxicity effects in rats. Additionally, a 12-month study in dogs also revealed that dietary supplementation with sucralose up to $30 \mathrm{~g} / \mathrm{kg} / \mathrm{d}$ had no adverse effects on the hematological and clinical chemistry assessed [32]. Otherwise, the studies for other sweeteners such as neotame in weaned piglets obtained similar results, no significant differences on hematological parameters and organ index were observed with dietary supplemented levels up to $500 \mathrm{mg} / \mathrm{kg}$ [7]. Hematological parameters play an important role in evaluating the physiological state and injuries caused by certain sub- 
stances [6]. Serum biochemical parameters reflect the health status of the kidney and liver functions and lipid metabolism [33]. Serum alanine aminotransferase and aspartate aminotransferase are commonly measured as clinical biomarkers for liver health [33]. In the present study, sucralose was found to be safe when fed to weaned piglets at a dose of $1,500 \mathrm{mg} / \mathrm{kg}$, which is an estimated 10 -fold higher dose than the commended optimal dose for weaned piglet. Therefore, the highest dose did not induce noticeable signs of toxicity.

\section{CONCLUSION}

This study indicated that dietary supplemental of sucralose may increase growth performance of weaned piglets. The concentrations of sucralose over $150 \mathrm{mg} / \mathrm{kg}$ may decrease palatability of feed and further reduce feed intake. Our results also showed that pigs could tolerate up to $1,500 \mathrm{mg} / \mathrm{kg}$ sucralose without adverse effect on their health. Therefore, supplementing $150 \mathrm{mg} / \mathrm{kg}$ sucralose for weaned piglets is recommended in this study.

\section{CONFLICT OF INTEREST}

We certify that there is no conflict of interest with any financial organization regarding the material discussed in the manuscript. $\mathrm{He} \mathrm{H}$ is an employee of Nanjing Jinhe Yikang Biotechnology.

\section{ACKNOWLEDGMENTS}

This work was supported by Nanjing Jinhe Yikang Biotechnology Co., Ltd, Nanjing, China. The authors are grateful to the company.

\section{REFERENCES}

1. Campbell JM, Crenshaw JD, Polo J. The biological stress of early weaned piglets. J Anim Sci Biotechnol 2013;4:19. https:// doi.org/10.1186/2049-1891-4-19

2. Pluske JR, Hampson DJ, Williams IH. Factors influencing the structure and function of the small intestine in the weaned pig: a review. Livest Prod Sci 1997;51:215-36. https://doi.org/ 10.1016/S0301-6226(97)00057-2

3. Dong GZ, Pluske JR. The low feed intake in newly-weaned pigs: problems and possible solutions. Asian-Australas J Anim Sci 2007;20:440-52. https://doi.org/10.5713/ajas.2007.440

4. Sterk A, Schlegel P, Mul AJ, Ubbink-Blanksma M, Bruininx EM. Effects of sweeteners on individual feed intake characteristics and performance in group-housed weanling pigs. J Anim Sci 2008;86:2990-7. https://doi.org/10.2527/jas.2007-0591

5. Lewis CJ, Catron DV, Combs JrGE, Ashton GC, Culbertson CC. Sugar in pig starters. J Anim Sci 1955;14:1103-15. https:// doi.org/10.2527/jas1955.1441103x

6. Aldinger SM, Speer VC, Hays VW, Catron DV. Effect of saccharin on consumption of starter rations by baby pigs. J Anim Sci 1959;18:1350-5. https://doi.org/10.2527/jas1959.1841350x

7. Zhu L, Wang G, Dong B, Peng CC, Tian YY, Gong LM. Effects of sweetener neotame on diet preference, performance and hematological and biochemical parameters of weaned piglets. Anim Feed Sci Technol 2016;214:86-94.

8. Kennedy JM, Baldwin BA. Taste preferences in pigs for nutritive and non-nutritive sweet solutions. Anim Behav 1972;20: 706-18. https://doi.org/10.1016/S0003-3472(72)80142-8

9. Wiet SG, Beyts PK. Sensory characteristics of sucralose and other high intensity sweeteners. J Food Sci 1992;57:1014-9. https://doi.org/10.1111/j.1365-2621.1992.tb14345.x

10. Horne J, Lawless HT, Speirs W, Sposato D. Bitter taste of saccharin and acesulfame-K. Chem Senses 2002;27:31-8. https:// doi.org/10.1093/chemse/27.1.31

11. Kuhn C, Bufe B, Winnig M, et al. Bitter taste receptors for saccharin and acesulfame K. J Neurosci 2004;24:10260-5. https://doi.org/10.1523/JNEUROSCI.1225-04.2004

12. Glaser D, Wanner M, Tinti JM, Nofre C. Gustatory responses of pigs to various natural and artificial compounds known to be sweet in man. Food Chem 2000;68:375-85. https://doi. org/10.1016/S0308-8146(99)00212-5

13. Roura E, Koopmans SJ, Lallès JP, et al. Critical review evaluating the pig as a model for human nutritional physiology. Nutr Res Rev 2016;29:60-90. https://doi.org/10.1017/S09544224 16000020

14. Grice HC, Goldsmith LA. Sucralose-an overview of the toxicity data. Food Chem Toxicol 2000;38(Suppl 2):S1-6.

15.Sims J, Roberts A, Daniel JW, Renwick AG. The metabolic fate of sucralose in rats. Food Chem Toxicol 2000;38(Suppl 2):S115-21. https://doi.org/10.1016/S0278-6915(00)00034-X

16. Magnuson BA, Roberts A, Nestmann ER. Critical review of the current literature on the safety of sucralose. Food Chem Toxicol 2017;106(Pt A):324-55. https://doi.org/10.1016/j.fct. 2017.05.047

17. Sylvetsky AC, Welsh JA, Brown RJ, Vos MB. Low-calorie sweetener consumption is increasing in the United States. Am J Clin Nutr 2012;96:640-6. https://doi.org/10.3945/ajcn.112.034751

18. Nofre C, Tinti JM. Neotame: discovery, properties, utility. Food Chem 2000;69:245-57. https://doi.org/10.1016/S0308-8146 (99)00254-X

19. Committee on Nutrient Requirements of Swine. National Research Council. Nutrient requirements of swine. 11th ed. Washington, DC, USA: National Academy Press; 2012.

20. Richer CP. Total self-regulatory functions in animals and human beings. Harvey Lect 1943;38:63-103.

21.AOAC. Official methods of analysis. 16th edition. Association of Official Analytical Chemists. Washington, DC, USA: AOAC International; 1995.

22.Shackelford C, Long G, Wolf J, Okerberg C, Herbert R. Qualita- 
tive and quantitative analysis of nonneoplastic lesions in toxicology studies. Toxicol Pathol 2002;30:93-6. https://doi.org/ $10.1080 / 01926230252824761$

23. Hellekant G. Preference for sweet and the taste of sweeteners in animals. Fortschr Tierphysiol Tierernahr 1980;11:43-52.

24. McLaughlin CL, Baile CA, Buckholtz LL, Freeman SK. Preferred flavors and performance of weanling pigs. J Anim Sci 1983;56:1287-93. https://doi.org/10.2527/jas1983.5661287x

25. Guzmán-Pino SA, Solà-Oriol D, Figueroa J, Dwyer DM, Pérez JF. Effect of a long-term exposure to concentrated sucrose and maltodextrin solutions on the preference, appetence, feed intake and growth performance of post-weaned piglets. Physiol Behav 2015;141:85-91. https://doi.org/10.1016/j.physbeh.2015. 01.009

26. Grotz VL, Munro IC. An overview of the safety of sucralose. Regul Toxicol Pharmacol 2009;55:1-5. https:/doi.org/10.1016/ j.yrtph.2009.05.011

27.Perina DD, Sbardella M, de Andrade C, et al. Effects of sorbitol or an antimicrobial agent on performance, diarrhea, feed digestibility, and organ weight of weanling pigs. Livest Sci 2014;164:144-8. https://doi.org/10.1016/j.livsci.2014.03.011

28. Munro PJ, Lirette A, Anderson DM, Ju HY. Effects of a new sweetener, Stevia, on performance of newly weaned pigs. Can Vet J 2000;80:529-31. https://doi.org/10.4141/A00-001

29. Schlegel P, Hall P. Effects of diet type and an artificial high intensity sweetener (SUCRAM ${ }^{\circledR}$ ) on weaned piglet performance. J Anim Sci 2006;84(Suppl 1):45-6.

30. Whitehouse CR, Boullata J, McCauley LA. The potential toxicity of artificial sweeteners. AAOHN J 2008;56:251-61. https://doi.org/10.1177/216507990805600604

31. Guido R, Gabriele A, Giovanna A, et al. Guidance on the assessment of the safety of feed additives for the target species. EFSA J 2017;15:5021. https://doi.org/10.2903/j.efsa.2017.5021

32. Goldsmith LA. Acute and subchronic toxicity of sucralose. Food Chem Toxicol 2000;38 (Suppl 2):S53-69. https://doi. org/10.1016/S0278-6915(00)00028-4

33. Obika M, Noguchi H. Diagnosis and evaluation of nonalcoholic fatty liver disease. Exp Diabetes Res 2012;2012:1-12. 